\title{
Ontogenetic Variation in Movements and Depth Use, and Evidence of Partial Migration in a Benthopelagic Elasmobranch
}

\section{OPEN ACCESS}

Edited by:

Yolanda E. Morbey,

University of Western Ontario, Canada

Reviewed by:

Paddy Walker,

Dutch Elasmobranch Society,

Netherlands

Jose A. Masero,

University of Extremadura, Spain

*Correspondence:

James Thorburn

jat21@st-andrews.ac.uk

† Joint last authors

Specialty section:

This article was submitted to Behavioral and Evolutionary Ecology,

a section of the journal

Frontiers in Ecology and Evolution

Received: 30 May 2019

Accepted: 06 September 2019

Published: 25 September 2019

Citation:

Thorburn J, Neat F, Burrett I, Henry L-A, Bailey DM, Jones CS and Noble LR (2019) Ontogenetic Variation

in Movements and Depth Use, and

Evidence of Partial Migration in a Benthopelagic Elasmobranch.

Front. Ecol. Evol. 7:353.

doi: 10.3389/fevo.2019.00353

\begin{abstract}
James Thorburn ${ }^{1 *}$, Francis Neat ${ }^{2}$, Ian Burrett ${ }^{3}$, Lea-Anne Henry ${ }^{4}$, David M. Bailey ${ }^{5}$, Cath S. Jones ${ }^{6+}$ and Les R. Noble ${ }^{7+}$
\end{abstract}

${ }^{1}$ Coastal Resource Management Group, Scottish Oceans Institute, University of St. Andrews, St. Andrews, United Kingdom, ${ }^{2}$ World Maritime University, Malmö, Sweden, ${ }^{3}$ Scottish Sea Angling Conservation Network, Stranraer, United Kingdom, ${ }^{4}$ School of GeoSciences, University of Edinburgh, Edinburgh, United Kingdom, ${ }^{5}$ Institute of Biodiversity Animal Health and Comparative Medicine, University of Glasgow, Glasgow, United Kingdom, ${ }^{6}$ School of Biological Sciences, College of Life Sciences and Medicine, University of Aberdeen, Aberdeen, United Kingdom, ${ }^{7}$ Faculty of Biosciences and Aquaculture, Nord University, Bodø, Norway

Tope (Galeorhinus galeus) is a highly mobile elasmobranch in the temperate to subtropical northeast Atlantic. It is highly migratory and has been shown to display complex movement patterns, such as partial migration, in the southern hemisphere. In the northeast Atlantic, previous mark-recapture studies have struggled to identify movement patterns and the species behavior is poorly described, yet identification of migratory behaviors and habitats of importance for the species is of paramount importance for effective management. Here, we combined fisheries independent survey data with markrecapture (MR) data to investigate the distribution of different age classes of tope across the northeast Atlantic. We further investigated depth use in detail with archival electronic tags and a pop-up satellite archival tag (PSAT). We suggest previous studies struggling to find consistent movement patterns using MR data were confounded by a combination of site fidelity, partial migration by females, and increasing depth and home range of juveniles. Survey and MR data showed immature tope $<40 \mathrm{~cm}$ were caught exclusively in continental shelf waters $<45 \mathrm{~m}$ deep, showing a significant relationship between habitat depth and total length. Immature individuals seemed to remain on the continental shelf, while mature tope of both genders were caught in both shelf and offshore waters. This use of deeper water habitats by mature tope was further supported by archival tags, which indicated individuals use both shallow (<200 m depth) and deep-water habitats, diving to depths of $826 \mathrm{~m}$; the deepest record for this species. The PSAT tag tracked the horizontal movements of an adult male, which confirmed utilization of both shallow inshore and deep offshore habitats. Most tope remained within $500 \mathrm{~km}$ of their tagging site, although some mature females had a larger, more southerly range, including connectivity with the Mediterranean. This study clearly demonstrates the highly migratory habits of tope, and suggests larger individuals divide their time between shallow and deep-water habitats. It shows the northeast Atlantic tope population should benefit from consistent management throughout its range.

Keywords: tope, school shark, depth range, archival tags, migration, site fidelity 


\section{INTRODUCTION}

Many elasmobranchs (sharks, skates, and rays) are highly mobile, ranging across regional seas (Mucientes et al., 2009) with some species undertaking trans-ocean movements (Templeman, 1976; Gore et al., 2008). They occupy a wide depth range, from surface waters to $3,000 \mathrm{~m}$ (Priede et al., 2006), with species displaying daily, yearly and life-long variations (e.g., Bres, 1993; West and Stevens, 2001; Sims et al., 2003; Andrews et al., 2009; Neat et al., 2014; Thorburn et al., 2015). These factors, together with the long lifespans of many elasmobranchs, present an opportunity for an individual to use many different geographic locations and habitats during its lifetime (Bres, 1993). Consequently, spatial management plans to conserve elasmobranchs across different habitats and sociopolitical regimes, including areas beyond national jurisdiction (the High Seas), is challenging. Hence, effective spatial management for mobile species may only be possible in situations where they display site fidelity to habitats critical for life history events, e.g., reproduction, and where such aggregations are at risk to anthropogenic pressures. It is crucial, therefore, to better understand and define behaviors that determine elasmobranch spatial ecology and the habitats and regions with which they are associated.

There is substantial evidence that elasmobranchs often remain within a home range (Carrier et al., 2012), i.e., a behaviorally confined geographic area, which may justify an element of spatial management in species conservation. Within this home range, they may exhibit daily, seasonal, and ontogenetic changes in depth use (Grubbs, 2010; Afonso and Hazin, 2015; Thorburn et al., 2015) and populations can segregate into sub-units based on age and sex (Bres, 1993; Wearmouth and Sims, 2008; Thorburn et al., 2018). This can give rise to complex patterns of spatial ecology at a population level, for example, juveniles will often remain within specific pupping/nursery grounds within the population's home range (Gruber et al., 1988). From here, they gradually increase their spatial use as they grow (Gruber et al., 1988) including an increase in their depth range (Grubbs, 2010; Afonso and Hazin, 2015). Many species also exhibit seasonal variation in depth, often in the form of a move to deeper, offshore waters during colder months, returning to shallower waters in the spring and summer (Andrews et al., 2009; Queiroz et al., 2010; Thorburn et al., 2015). These seasonal movements are mostly attributed to the reproductive cycle (Hurst et al., 1999), temperature requirements, or dietary needs (Bres, 1993; Wearmouth and Sims, 2010). Some species also display a dietary shift as they move over the shelf edge to deeper waters, changing foraging strategies to presumably utilize the most locally abundant prey species (Queiroz et al., 2010).

Tope, or soupfin shark, (Galeorhinus galeus), classified as Vulnerable by the IUCN, are generally considered a benthopelagic species, meaning that they occupy most of the water column and are therefore potentially vulnerable to multiple pressures from human activities from the surface to the seafloor. They occupy a wide temperature range of $8.1^{\circ} \mathrm{C}-27^{\circ} \mathrm{C}$ (West and Stevens, 2001; Cuevas et al., 2014;
Rogers et al., 2017) and are distributed throughout the northeast and southeast Pacific, the northeast and southern Atlantic, Mediterranean Sea, off southern Australian and New Zealand waters (Compagno, 1984; Walker, 1999). Parturition occurs in shallow coastal waters (Hurst et al., 1999; McAllister et al., 2015) where juveniles remain within the confines of their nursery grounds for up to 2 years before expanding their home range (McAllister et al., 2015). They are capable of longdistance migratory behavior, with the greatest migration distance estimated to be $4,940 \mathrm{~km}$ (Hurst et al., 1999). Tope populations segregate by age and sex class sub-units (Lucifora et al., 2004), which display different movements and habitat choices (Hurst et al., 1999; Walker, 1999; Lucifora et al., 2004).

In the northeast Atlantic, tope occur from Iceland to the Azores and Canary Islands and are also found in the Mediterranean (Capapé et al., 2005). Conventional markrecapture (MR) data have shown some transboundary movement between these areas including some movement across oceanic waters (Holden and Horrod, 1979; Sutcliffe, 1994; Little, 1995, 1998; Fitzmaurice et al., 2003; Capapé et al., 2005), but have been unable to identify clear seasonal patterns (Stevens, 1990). Broadly they suggest that mature females display an annual southerly migration to pupping areas in the south (Holden and Horrod, 1979; Stevens, 1990; Sutcliffe, 1994; Little, 1998; Fitzmaurice et al., 2003), utilizing different grounds off Portugal and the Canary Islands (Munoz-Chapuli, 1984). However, there does appear to be variation in migratory behavior, as some females appear to remain within the proximity of their northern European tagging sites for most of the year (Holden and Horrod, 1979; Sutcliffe, 1994; Little, 1995) while others undertake offshore movements over the winter including movements to these more southerly areas (Wheeler, 1969; Stevens, 1990). It has been suggested that mature female tope in the Mediterranean display partial migrations (Capapé et al., 2005), some females remaining within a limited home range to pup, while others undertake longer migrations to pupping sites outside the home range (Capapé et al., 2005); this would be similar to behavior observed in Australasia (McMillan et al., 2018b) linked to discrete pupping grounds (McMillan et al., 2018a,b). It was further suggested that females displaying residential behavior may reproduce every year because they can allocate more energy to reproduction, whereas those following a more demanding migratory strategy are only able to reproduce every second year (Capapé et al., 2005).

On the basis of these studies, tope clearly has a complex spatial ecology, but there is no clear consensus on movement behaviors. The aim of this study was to consolidate data from a variety of sources in an effort to better define the movements of tope within the northeast Atlantic, and to assess evidence for site fidelity, propensity to aggregate, preferential habitat use, and investigate possible relationships between size, sex, and life history stage. A combination of survey data and mark and recapture data were pooled to understand the species' movements in this area for which there is currently limited data. We also deployed multiple archival electronic tags and 1 pop off satellite archival tag (PSAT) on a tope captured off southern Scotland. 


\section{MATERIALS AND METHODS}

\section{Data Collection}

\section{Mark-Recapture and Survey Data}

Mark and recapture (MR) data were combined from the Scottish Shark Tagging Program (SSTP), the Glasgow Museum Tagging Program (GMTP), the UK Shark Tagging Program (UKSTP), and Holden and Horrod (1979). All MR data consisted of conventional ID mark and recapture data. In most cases, but not all, data consisted of date of capture, location of capture in either longitude and latitude format or verbal description, stretched total length (TL), weight either measured or estimated from TL, and gender. Recaptures were reported by anglers and commercial vessels. Fisheries-independent survey data for tope up to and including 2014 were downloaded from the International Council for the Exploration for the Sea (ICES) Database of Trawl Surveys (DATRAS) portal (https://datras.ices.dk/), with catch location assigned as trawl retrieval latitude and longitude. Data were filtered so only records with length measurements (TL) were used (NS-IBTS, BTS, and EVHOE). These data were added to the MR data to create a Presence Dataset. For all data, individuals were assigned a maturity status, either mature or immature, based on $\mathrm{TL}$ at time of capture. Males were deemed to be mature at TL $\geq 126 \mathrm{~cm}$ (Capapé et al., 2005) and females with TL $\geq 130 \mathrm{~cm}$ (Lucifora et al., 2004). In instances where no TL was recorded for the recapture, length was estimated from weight at recapture using length-weight charts developed by both the UK Shark Tagging Programme (www.ukstp.co.uk) and the Scottish Shark Tagging Program (www.tagsharks.com). If no weight or length was recorded at recapture, TL was either measured or estimated from weight at time of tagging if the recapture was within 1 year. Records of recapture were used to form a separate Recapture Dataset. Records where the recapture did not match the tagging record (i.e., gender change, or unrealistic length differences) were removed. The straight-line distance (Distance) and days at liberty (Freedom) between tagging and recapture event were calculated for each tag number, and dates were assigned a day of year (1-365). The exceptions to this were recaptures in the Mediterranean, for these, minimum wet distance (avoiding land) was calculated rather than straight-line. In total, 2,043 records, both tag and recapture, were collated. Of these, 138 recapture records were useable [53 males: 13 immature $(84-126 \mathrm{~cm}), 40$ mature $(126.1-168 \mathrm{~cm})$; 85 females: 40 immature $(86-130 \mathrm{~cm})$, 45 mature $(130.1-180 \mathrm{~cm})]$, having both a location of capture and recapture and at least one TL record per individual. Filtered DATRAS data produced 457 records between 1984 and 2011.

\section{Archival and PSAT Tagging}

Tope were caught using individual baited hook and line in Luce Bay, southwest Scotland $\left(54.7^{\circ} \mathrm{N}, 4.7^{\circ} \mathrm{W}\right.$; Figure 4). Tags were deployed over three periods; June 2012 (Archival tags: Star Oddi centi-TD, $n=5$ ), September 2014 (Archival tags: Lotek LAT2900XW, $n=10$ ), and October 2015 (PSAT tag: Wildlife computer MiniPAT, $n=1)$. Total length (TL) and gender were recorded. All tags were pre-started and fitted externally. Star Oddi tags were mounted on a silicone pad and anchored through the base of the first dorsal fin using two stainless steel pins and
Peterson disks. Lotek tags, fitted with an external float jacket, were attached via 200lb nylon with a rubber tube casing and inserted through the dorsal spine at the base of the first dorsal fin using a sterilized stainless-steel needle at a minimum of $3 \mathrm{~cm}$ from the trailing edge. Once through, the nylon was crimped to itself, creating a loop. The PSAT tag was attached intramuscularly using a titanium plate inserted into the dorsal musculature next to the first dorsal fin. The plate was pushed in place using a sterilized stainless-steel applicator. A 200lb monofilament leader of $5 \mathrm{~cm}$ was attached the tag to the plate. The PSAT tag was preprogrammed to release after 180 days. All tags were marked with a specific ID number. Star Oddi tags were set to record depth and temperature every $5 \mathrm{~min}$. Lotek tags recorded depth and temperature every $10 \mathrm{~min}$, their wet/dry state every $40 \mathrm{~min}$, and light levels every $2 \mathrm{~min}$, while the PSAT was set to record depth every 5 min with temperature summarized every $24 \mathrm{~h}$ (Table 2). Tagged animals were released at their capture site within Luce Bay. Tags were marked with contact details and notice of a cash reward for their return.

\section{Data Analysis}

\section{Mark-Recapture and Survey Data}

\section{Site associations}

A Generalized Additive Model (GAM) was used to investigate the relationship between Distance, day of year, gender and maturity status in R ( $\mathrm{R}$ Core Team, 2013) using the MGCV package (Wood, 2001). Distance was log-transformed to reduce the impact of outliers. Day of year was smoothed using a cyclic penalized cubic regression spline. Model choice was based on the Akaike's Information Criterion (AIC).

\section{Ontogenetic and sex difference in ranges}

Using the Recapture Dataset, the relationship between Distance traveled, gender, and size was investigated using linear models in R 3.1.3 (R Core Team, 2013) with distance modeled as a function of TL and gender. As we were interested in the furthest Distance traveled per age class, length data from MR recaptures for each sex were divided into $5 \mathrm{~cm}$ length classes. Distance was taken to be the maximum distance traveled by an individual from each length class.

\section{Immature tope spatial use}

To provide a geographic representation on the size distribution of tope, the Presence Dataset was interpolated using kriging methods with a spherical model in ArcGIS 10.2. Kriging interpolation is better suited to clustered data than other methods as it helps to compensate for the effect of non-uniform effort on the data. Kriging was based on the minimum TL value recorded at locations where there were multiple individuals caught in order to identify areas important to smaller tope. Data were grouped into $10 \mathrm{~cm}$ length classes for visualization, starting at $26 \mathrm{~cm}$ based on the record for the smallest TL recorded. To investigate the maximum water depth use by immature tope, water depth for each presence data point was extrapolated from GEBCO bathymetric data extracted at a 1-min arc cell size in ArcGIS 10.2 based on the latitude and longitude of that point. Data were split into TL classes of $5 \mathrm{~cm}$ increments up to $130 \mathrm{~cm}$, and the 

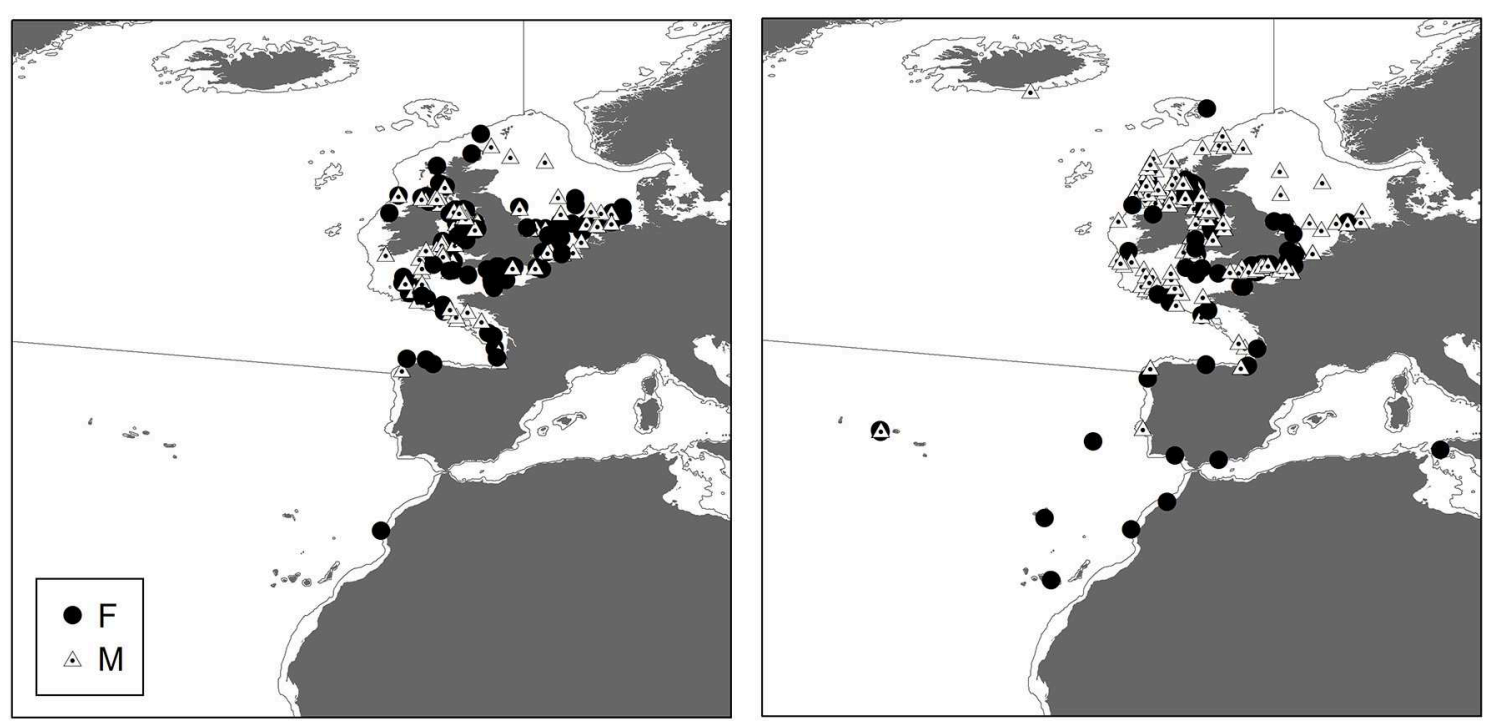

FIGURE 1 | Distribution of immature and mature tope with gender symbolized from presence data, combining mark-recapture, and International Bottom Trawl Survey (IBTS) data. (Left) Distribution of immature tope $(\mathrm{m}<126 \mathrm{~cm}, \mathrm{f}<130 \mathrm{~cm})$. (Right) Distribution of mature tope $(\mathrm{m} \geq 126 \mathrm{~cm}, \mathrm{f} \geq 130 \mathrm{~cm})$.

maximum water depth for each length class was recorded from the deepest water record within each size range. This method was undertaken to look at maximum water depth occupied by each size class. Relationships between TL and maximum depth were explored using linear models (LM) with depth as a function of TL and gender in R 3.1.3 (R Core Team, 2013).

\section{Archival and PSAT Tag}

Depth was smoothed to 30-min averages and wavelet transformation analysis (Rösch and Schmidbauer, 2014) used to look for cyclic patterns. Wavelet analysis was undertaken in the R package WaveletComp (Rösch and Schmidbauer, 2014) on the smoothed depth data obtained from all archival and PSAT tags using the following parameters: loess span $=$ $0.1, \mathrm{dt}=0.5, \mathrm{dj}=1 / 250$, lowerPeriod $=8$, upperPeriod $=$ 256 (30 min average data were used, so to define the range of periods in time steps the analysis searches 8 steps $=4 \mathrm{~h}$ and $256=128 \mathrm{~h}$ ), n.sim (number of simulations) $=100$. See Rösch and Schmidbauer (2014) for a full description of these parameters. Geolocation was not undertaken on archival tags due to large amounts of uncertainty around the geographical position of the end of the tag record and the lack of temperature data in two of the tags. A Maximum Likelihood Path was recreated for the PSAT tag with geographic positions being estimated using Wildlife Computers' own state-space GPE3 model, which produces maximum likelihood positions with 50, 95, and 99\% confidence estimates, while latitude and longitude are estimated using light levels (dawn, dusk, and noon) that are further refined using sea surface temperature (SST) and bathymetry data. The GPE3 model was run using a swimming speed of $1 \mathrm{~ms}-1$ based on previous PSAT tagging research on G. galeus in the southern hemisphere (McMillan et al., 2018b).

\section{RESULTS}

\section{Presence Data}

Male and Female immature tope were found throughout the north-eastern Atlantic continental shelf (Figure 1, left panel). Besides shelf environments, mature individuals of both genders were also found in oceanic waters, with mature females inhabiting more southerly waters around the Azores and the Canary Islands (Figure 1, right panel), while mature males were more regularly found in northerly waters off northwest Scotland. The length distribution map (Figure 2) suggests that tope $<46 \mathrm{~cm}$ long were found in coastal waters. Juvenile tope (males $<126 \mathrm{~cm}$, females $<130 \mathrm{~cm}$ ) were absent in oceanic waters and from more southerly latitudes and tope $<40 \mathrm{~cm}$ were found in coastal waters in the southern North Sea and off the west coast of England and Wales. Most tope were captured in $\leq 50 \mathrm{~m}$ (Figure 3, left panel), however, there was a significant linear relationship between maximum environmental water depth and total length, with larger tope being found in increasing water depths (Figure 3, right panel). Gender did not have a significant effect on maximum depth use.

\section{Mark-Recapture}

Recaptures of immature tope occurred on average $314.85 \mathrm{~km}$ away from the original tagging site, with a difference of $103 \mathrm{~km}$ between the average distances traveled by males and females $(\mathrm{F}=366.4, \mathrm{M}=263.3$, Table 1$)$. The average distance traveled by mature individuals showed greater variation, with mature males recaptured on average $342.8 \mathrm{~km}$ (maximum $2,168 \mathrm{~km}$ over 2,000 days) from their tagging site, similar to average distances seen in immature males; females were captured on average $799.1 \mathrm{~km}$ (maximum 3,900 km over 1,960 days) away, over double that shown by immature females (Table 1). Most 


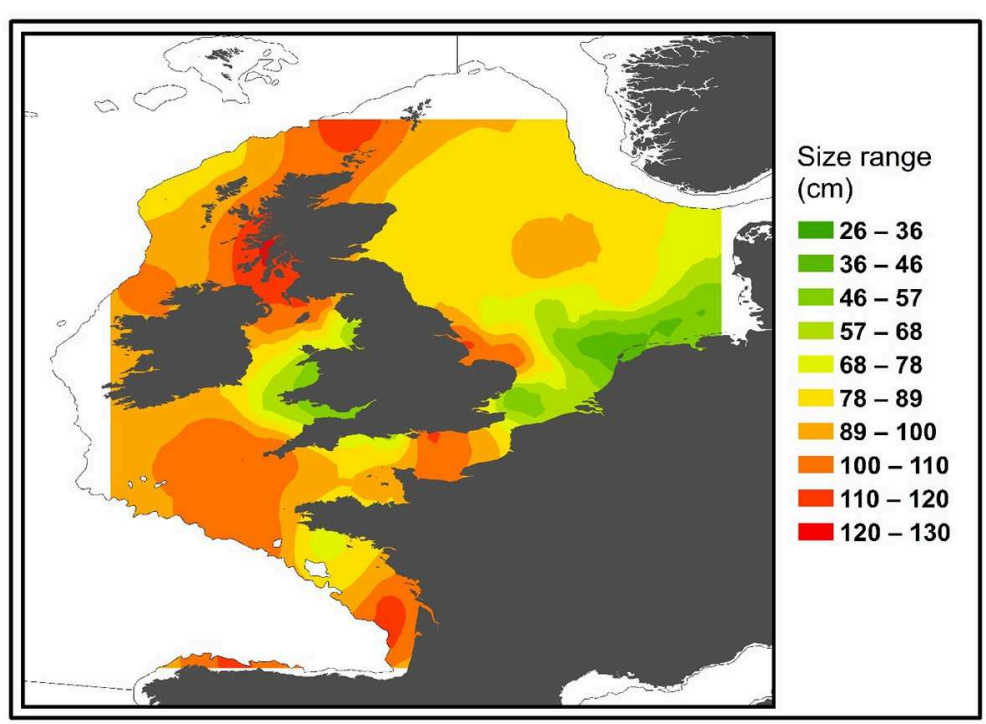

FIGURE 2 | Distribution of all immature tope (max length = $130 \mathrm{~cm}$ ) based on mark and recapture and International Bottom Trawl Survey (IBTS) data sets. Color represents smallest sized (based on total length) animal predicted to occur in that area. Smoothing was performed using kriging methods on minimum total length at each site using ArcGIS 10.2 .

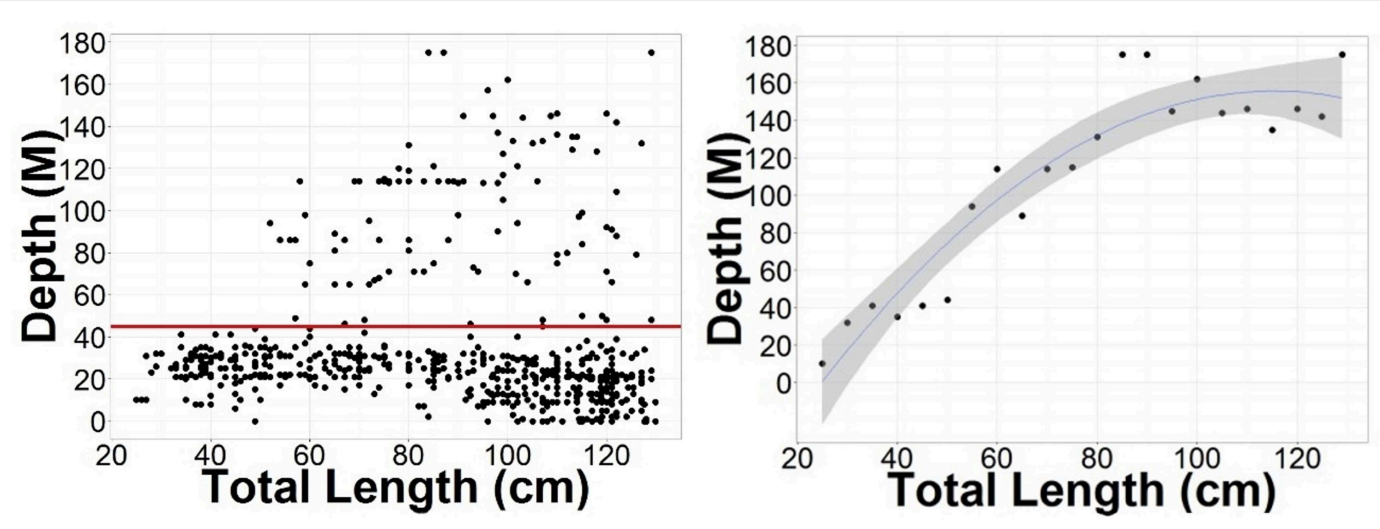

FIGURE 3 | (Left) Depth distributions compared to the length of tope recaptured in the northeast Atlantic from mark-recapture data sets, with a red line at $45 \mathrm{~m}$ to signify the depth limitation of tope $<50 \mathrm{~cm}$ long. (Right) Points show the maximum water depth reached by each $5 \mathrm{~cm}$ length class. Blue line represents a polynomial linear model with depth as a function of Total Length. Adjusted $R^{2}=0.8778, \mathrm{DF}=19, p=8.186-10$. Gray ribbon represents standard error.

males, both immature and mature, were recaptured within the confines of the continental shelf, except for one mature male recaptured of the coast of Iceland after being tagged in Scotland and one being recaptured in the Azores after being tagged in Scotland (Figure 4, left panel). Immature females were, similarly to males, recaptured on the continental shelf. However, there were several examples of mature females, after being tagged around the coast of the UK, being recaptured in the Azores, the Canary Islands and in the Mediterranean Sea (Figure 4, right panel). Maximum range traveled by female tope significantly increased with body length (Figure 5, Table 1), but females $<95 \mathrm{~cm}$ did not have ranges larger than $500 \mathrm{~km}$ (Figure 5). There was no significant relationship between TL and maximum range traveled by males, and maximum distance traveled varied considerably as TL increased (Figure 5), however, the minimum male recapture length of $84 \mathrm{~cm}$ prevented investigation of a range of smaller animals. General Additive Modeling (GAM) of recapture data showed that the day of year of recapture had the most significant influence on distance from tagging site, accounting for 30\% of the deviation seen in distance traveled; gender and TL did not improve the model (Figure 6). The GAM shows a general population trend of all size and sex classes moving away from their tagging site over winter and spring, returning to an area near their original tagging site $(<50 \mathrm{~km})$ during summer and autumn (Figure 6). 
TABLE 1 | Summary of distance traveled by tope of each sex and maturity state from all tagging data showing median, mean, and maximum distance traveled in kilometers as well as number of records.

\begin{tabular}{|c|c|c|c|c|c|}
\hline Sex & Maturity state & Median & Mean & Max & Number \\
\hline \multirow[t]{3}{*}{ Female } & All ages & 323.9 & 624.2 & 3,900 & 85 \\
\hline & Immature & 125.1 & 366.4 & 2,017 & 40 \\
\hline & Mature & 393.7 & 799.1 & 3,900 & 45 \\
\hline \multirow[t]{3}{*}{ Male } & All ages & 87.4 & 315.1 & 2,168 & 53 \\
\hline & Immature & 142.7 & 263.3 & 844 & 13 \\
\hline & Mature & 71.3 & 342.8 & 2,168 & 40 \\
\hline
\end{tabular}
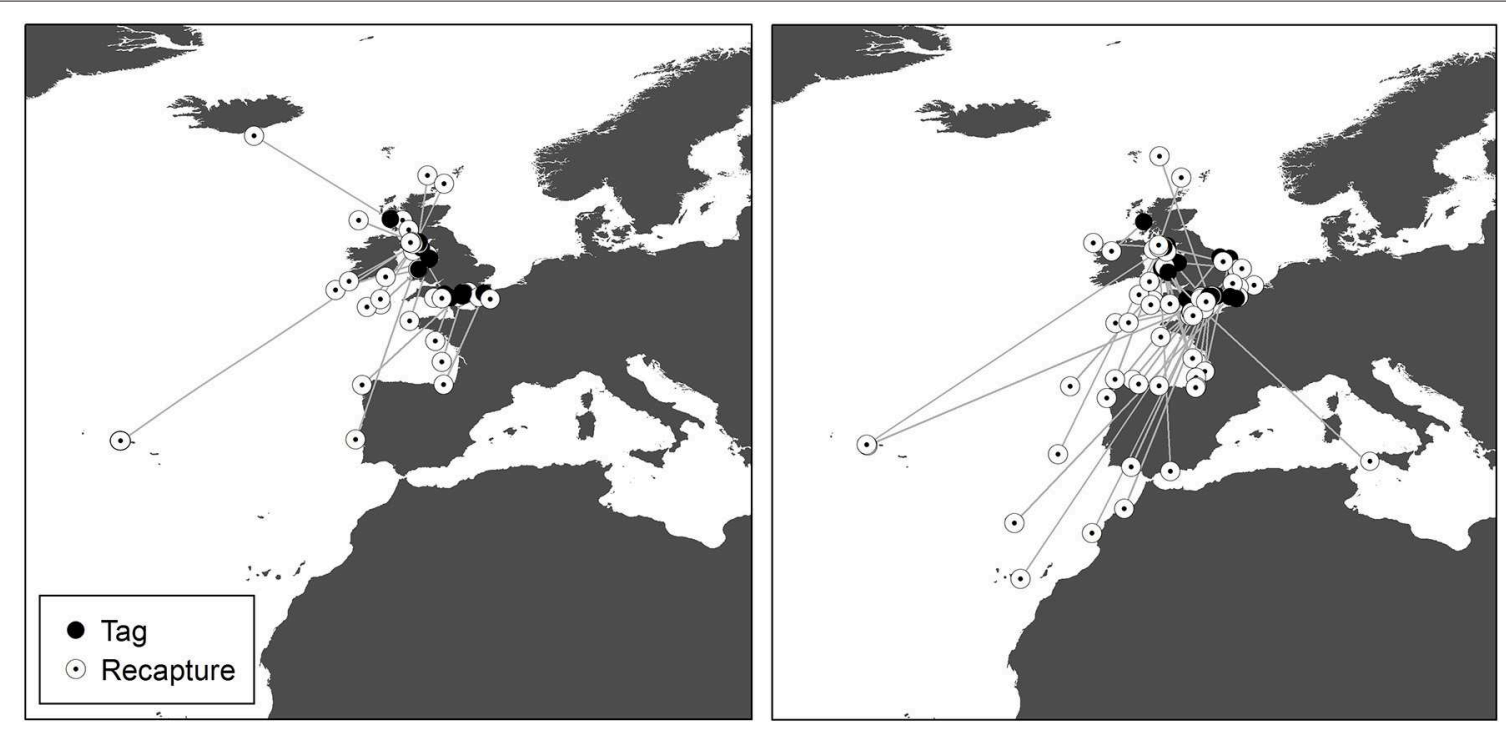

FIGURE 4 | Recaptures of tope tagged around the UK from the Scottish Shark, Glasgow Museums and UK Shark Tagging Programmes with a straight-line connector. Left, male; Right, female.
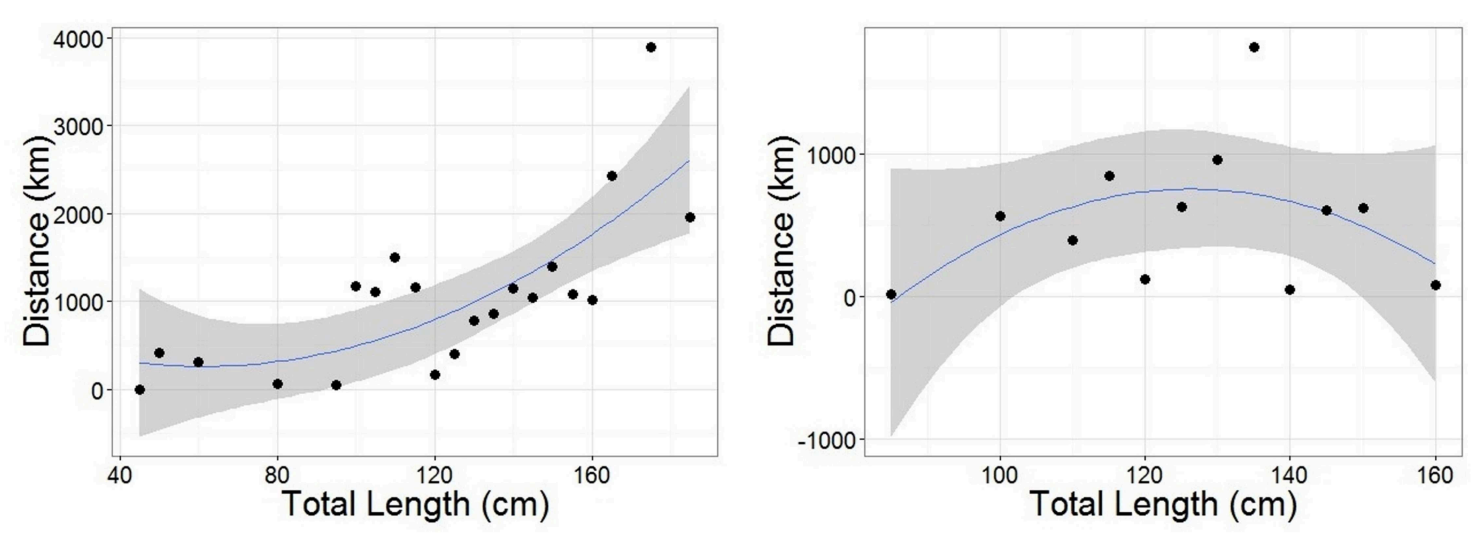

FIGURE 5 | Polynomial linear models of distance between tagging and recapture positions as a function of Total Length for females (Left) and males (Right). Length data were grouped into $5 \mathrm{~cm}$ classes. Distance was representative of the straight-line distance traveled by an individual from each length class (avoiding land for recaptures in the Mediterranean). Female model statistics: adjusted $R^{2}=0.521, \mathrm{DF}=18, p<0.05$. Male model statistics: adjusted $R^{2}=0.0783$, DF $=9, p=$ 0.2809. Gray ribbon represents standard error. 


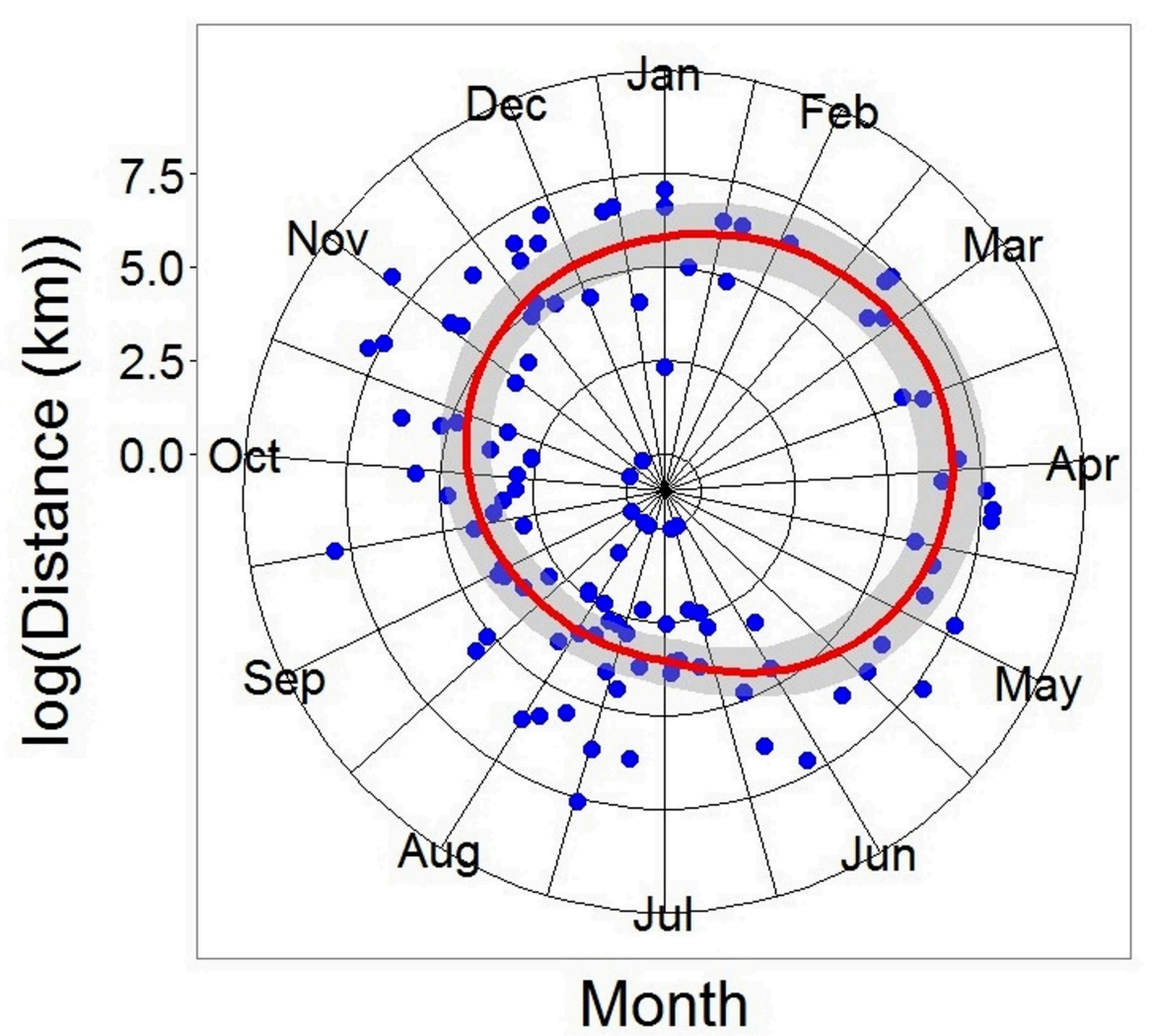

FIGURE 6 | Generalized Additive Model of all recaptured tope from the recapture. Distance modeled as a function of log (day of year of recapture). DF $=110, R^{2}=$ $0.297, p<0.05$. Gray ribbon represents the Standard Error.

TABLE 2 | Details of tope tagged with tags from which data were recovered.

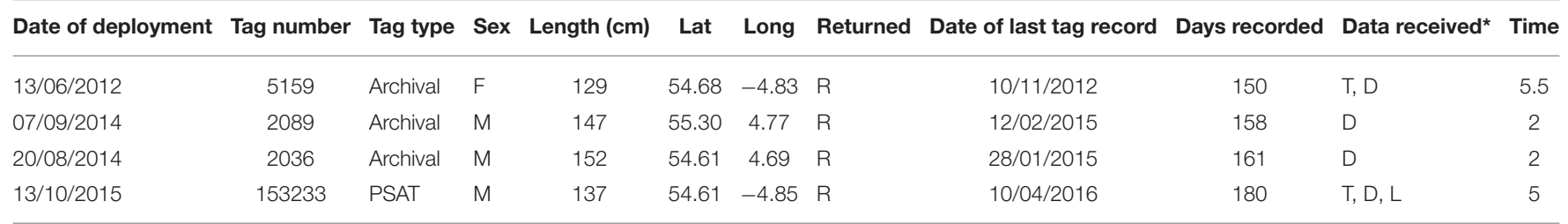

*Data received: the data types that the tag was programmed to record; T, Temperature; $D$, Depth; L, Light. Time: length of recording interval (minutes) for each parameter in the Data received column. For Tag 153233, only depth was recorded as a series, temperatures were binned over $24 \mathrm{~h}$ and light levels were used for on-board geo-location estimates but not recorded as a series.

\section{Archival and PSAT}

Overall, 5 archival tags were recovered, 1 Star oddi and 4 Lotek. Depth data between 150 and 161 days were recovered from 3 of these (1 Star oddi and 2 Lotek), temperature records were recoverable from only the star oddi tag (Table 2). Data were also recovered from PSAT tag via satellite transmission after the full 180 days deployment time (Table 2). The Star oddi tag was recaptured off the Portuguese coast (un-disclosed location) in March 2013, 129 days after the end of the tag record. The 4 lotek tags were all found on the western coast of the UK by beachcombers (minimum 585 days after the end of tag record). Tag 2089 remained in water shallower than $200 \mathrm{~m}$ until the 12th October, when it started occupying waters up to $300 \mathrm{~m}$ deep during the day. During this time, there was some evidence of standard and crepuscular diurnal migrations (Figure 7). However, diel patterns were generally weak compared to other tags. On the 20th January, 2089 moved to deeper water (max depth 542.5), upon which a strong diel pattern was initiated; occupying waters $<100 \mathrm{~m}$, including surface waters ( $<5 \mathrm{~m}$ deep), during hours of darkness, moving to depths between 400 and 664.5 (max depth) during daylight (Figure 7). Tag 2089 was found on the Isle of Arran off western Scotland 936 days after the last data record. Tag 153233 detached after the programmed 180 days, on the 11th April 2016 at latitude $51.59^{\circ} \mathrm{N}$, longitude $11.86^{\circ} \mathrm{W}$ (Figure 7). It remained between surface waters and $300 \mathrm{~m}$ depth until January. Wavelet analysis did not detect 


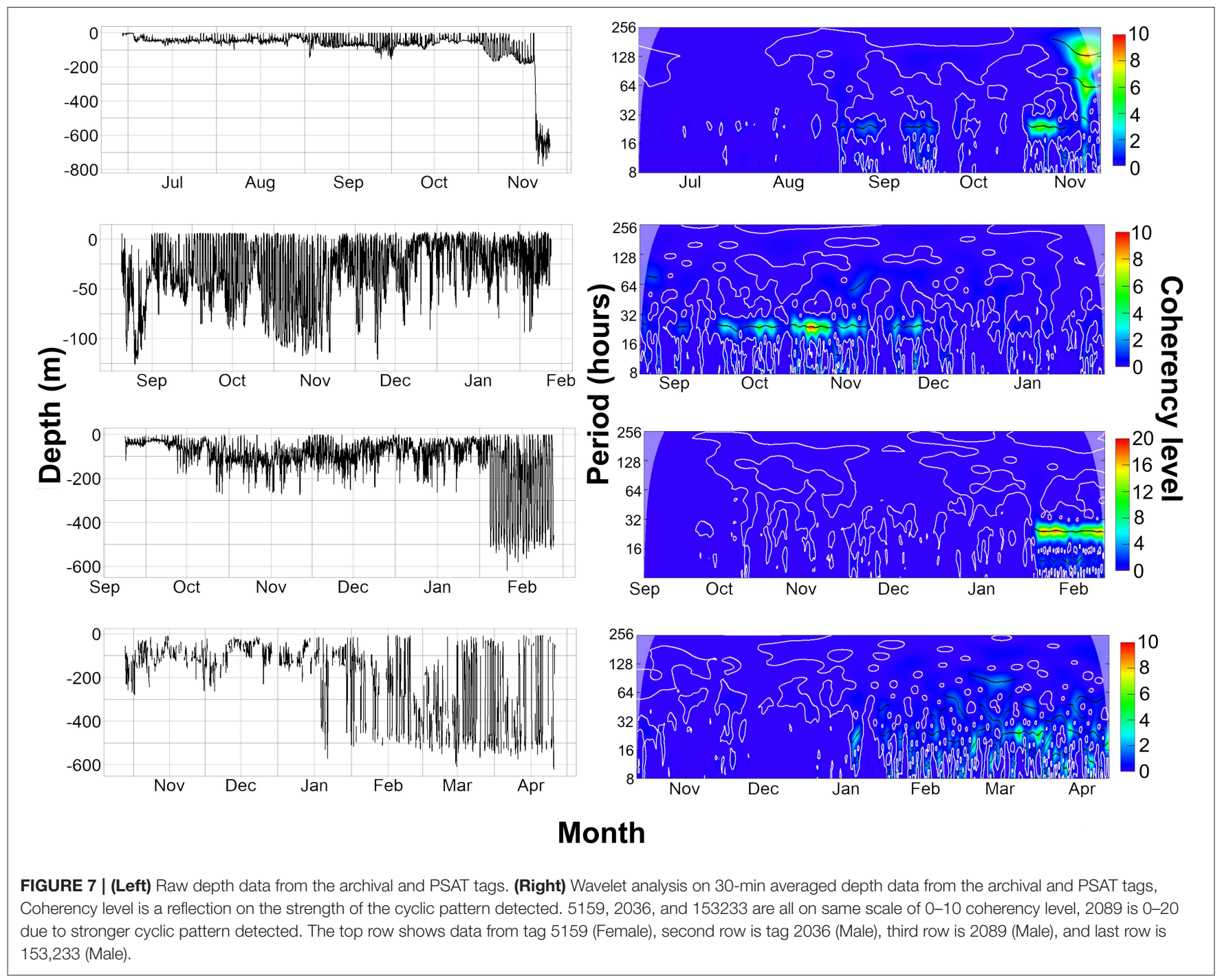

strong cyclic patterns during this time, but this may be due to incomplete data transmission creating gaps in the time series. On the 3rd January, 153233 increased its vertical range and occupied the water column from the surface to $644 \mathrm{~m}$ over the course of 4 days. From the 7 th to 13 th January, it moved back to a shallower depth range, between the surface and $175 \mathrm{~m}$. On the 14th January, 153233 occupied a wider depth range again, from surface waters to 654.5 (max depth), until the end of the tag record. While the time series was broken, enough data were recovered for a strong $24 \mathrm{~h}$ cyclic pattern to be detected during the times when 153233 moved to deeper water (Figure 7). Both standard and crepuscular diurnal migration were observed during these periods (Figure 7). The most likely pathway recreation for tag 153233 shows the tope leaving southwest Scotland, traveling west passing Northern Ireland toward the shelf edge (Figure 8). In December, it moved over the edge of the shelf, continuing to head west toward Rockall Bank (Figure 8). In January, its westward trajectory turned southwards, passing between the continental shelf and Porcupine Bank off of Ireland (Figure 8). The distance traveled was reduced in March, with the tope remaining in the channel to the east of Porcupine Bank (Figure 8). The tag detached after 180 days north of the deep Porcupine Seabight (Figure 8).

\section{DISCUSSION}

Tope in the northeast Atlantic are currently considered one large population dispersing throughout the region (Holden and Horrod, 1979; Stevens, 1990; Sutcliffe, 1994; Little, 1998; Fitzmaurice et al., 2003). We found no evidence to contradict this; the tope in this study showed high migration potential across the northeast Atlantic, even into the Mediterranean as far as Sicily (first reported in Colloca et al., 2019). The extent of migration appears to relate to age and gender, with adults having more latitudinal variation, as seen in other elasmobranch species (Olsen, 1954; Gruber et al., 1988; Speed et al., 2010), and females being found in more southerly waters and males in more northerly waters. The MR data also suggested that mature tope may have a greater latitudinal range than immature tope. Physical differences, dietary and habitat requirements, 


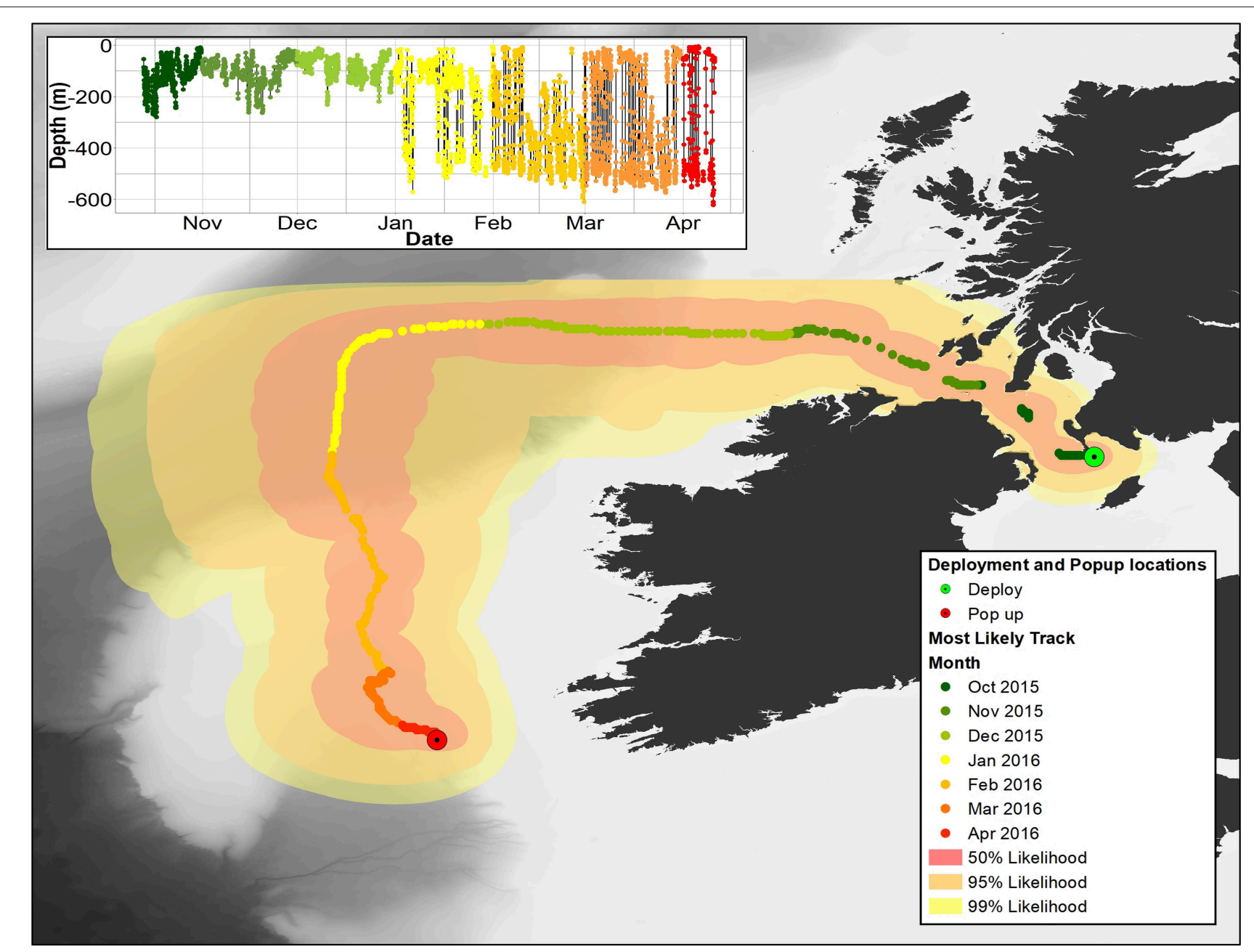

FIGURE 8 | Main image: most likely pathway for 153233 recreated using Wildlife Computers GPE3 model. 50, 95, and 99\% confidence limits are also shown. Insert: depth data for 153233. In both panels, months are color coded as per the legend.

reduction in resource competition, females avoiding mating, and the reduction of pup mortality can often result in different age and sex classes utilizing different geographic areas and depths (Klimley, 1987; Economakis and Lobel, 1998; Pratt and Carrier, 2001; Wearmouth and Sims, 2010). The variation in latitudinal extremes may be a product of females using warmer waters (Hurst et al., 1999; Robbins, 2007) to decrease embryonic development time (Economakis and Lobel, 1998) and reduce pup mortality (Hanchet, 1991), while males may use cooler water to optimize sperm production (Wearmouth and Sims, 2008). However, the presence of female tope around the Shetland Isles, and a male being recaptured in the Azores suggests temperature alone may not impact gender distribution greatly.

Globally, there is evidence that tope use shallow coastal waters, such as bays and estuaries, as nursery grounds (Hurst et al., 1999; McAllister et al., 2015; Bovcon et al., 2018). This was supported by analysis of the Presence data, where tope $<40 \mathrm{~cm}$ were only found in coastal regions and then seemed to expand their range, including depth, when they reached $50 \mathrm{~cm}$. This is reminiscent of juvenile behavior in the southern hemisphere, where tope under 2 years old remain within coastal nursery areas before expanding their home range (McAllister et al., 2015).

It appears that the majority of the tope population display similar movements based around a cyclic annual migration. It should be noted though that this is based on the Recapture data which was only available for tope $84 \mathrm{~cm}$ or larger. Due to the apparent depth limitations of juvenile tope shown by the Presence data, it is likely smaller tope have more spatially restricted home ranges, as observed in other elasmobranch species (Kinney and Simpfendorfer, 2009). The extent of this annual migration could be the basis for determining the population's core home range. This is further strengthened by the average distance mature males are recaptured from their tagging location being similar to that of immature tope of both genders. A caveat here is that data were only available for 13 immature 
male tope, so the movements of immature males could not be fully explored.

While most of the recaptured males, both mature and immature, were in shelf waters, the maximum recapture distance for mature males is significantly higher than immature tope of either gender. This is caused by a recapture in the Azores, one of two recapture records which show mature males do make wider movements and cross oceanic water. This is congruent with the findings from the archival data that mature males move into deeper water over the shelf edge. Mature female tope appear to display differing intra-gender migration strategies. While some mature females were recaptured at similar ranges to mature males and immature individuals, on the continental shelf within $500 \mathrm{~km}$ of the tagging site. Others were recaptured in southerly areas around the Azores and the Canary Islands, as has been observed previously (Sutcliffe, 1994; Little, 1995), producing a high average distance between capture and recapture sites for mature females.

This variation in movement distance displayed by females may be caused by gravid and non-gravid individuals undertaking discrete movements, as has been observed in other elasmobranch species in these two states (Howey-Jordan et al., 2013; Papastamatiou et al., 2013). That non-gravid females remain within the population's core home range while gravid females migrate to southerly nursery grounds has been suggested before (Sutcliffe, 1994; Little, 1995; Capapé et al., 2005). Small tope would then leave nursery grounds and migrate northwards as they grow (Holden and Horrod, 1979; Sutcliffe, 1994; Little, 1995). However, if this were the case, we would not expect to find evidence of nursery areas in more northerly regions as we did in this study, with tope $<40 \mathrm{~cm}$ being caught in coastal waters in the southern North Sea and elsewhere around the UK. This suggests that pupping occurs in both southerly and more northerly areas, and that gravidness is not responsible for the difference observed in mature female movements.

Mature females of other species of elasmobranch have been shown to display partial migration in relation to nursery sites, whereby some individuals make use of nursery grounds within the populations home range, while others make extended movements to more distant nursery grounds (Mourier and Planes, 2013; Papastamatiou et al., 2013). A similar behavior has been observed in southern hemisphere tope, where some females used pupping grounds within core home ranges, while others undertook wider movements to discrete pupping areas further afield (McMillan et al., 2018a,b).

Given the occurrence of northerly pupping grounds within the apparent core home range of the northeast Atlantic, it is likely that this strategy is undertaken by female tope in this region. We suggest concurrent use of pupping grounds in both the southerly and more northerly areas causes partial migrations in northeast Atlantic female tope, with some undertaking longer migrations to southern pupping grounds, while others remain within the populations apparent core home range, using more local pupping sites. There is some previous evidence of northeast Atlantic female tope displaying partial migration in the Mediterranean (Capapé et al., 2005), where two groups of gravid females were observed; one residential, the other migratory. The residential females were able to undergo vitellogenesis and gestation concurrently, shortening the reproductive cycle to 1 year, while females in the other group were only able to undertake one of these processes at a time due to a decreased energy budget for reproduction, doubling the length of the reproductive cycle. This variation in reproductive strategies may explain conflicting reports on the length of the reproductive cycle in female tope with annual (Ripley, 1946; Capapé et al., 2005), biennial (Olsen, 1954), and triennial (Lucifora et al., 2004) cycles all reported. The determination of which nursery grounds, and therefore reproductive strategy, are used by the female may be determined by philopatric behavior (well-documented in elasmobranchs Pratt and Carrier, 2001; Feldheim et al., 2002; DiBattista et al., 2008; Jorgensen et al., 2010), which has been shown to cause dispersal to multiple nursery sites (Hueter et al., 2005).

Movement in relation to nursery grounds does not appear to be the only migratory driver in northeast Atlantic tope, as there appears an annual cycle; with all age and sex classes being recaptured closer to their tagging sites during summer months and further away over winter. Site fidelity, which would cause an annual movement similar to that observed, has also been shown in elasmobranchs (Carrier et al., 2004). Mating has been shown to occur concurrently at different sites around the UK in June, including Luce Bay in Scotland to the Channel Islands (personal observation). Fidelity to these different mating grounds would cause an annual cyclic pattern, similar to that observed in this study, with adults being captured closer to a mating site over mating months (summer) and further away during winter. As all mating grounds are not in one location this suggests that tope annual migrations would not display a "north-south" pattern, explaining why previous studies using mark and recapture data struggled to find consistent patterns, as seasonal movements are in relation to tagging site rather than latitudinal position. The recapture of a single male in the Azores is not enough to infer partial migration in mature male tope, it is possible that after pupping, mature females are ready to mate and there are southerly mating grounds near pupping sites to which mature males travel, this requires further evidence to substantiate but would not explain the movement of the male tope to Iceland.

Movements may, as is common in elasmobranchs, be associated with prey migrations (Hussey et al., 2009; Papastamatiou et al., 2013), which would impact the movement of both mature and immature tope. The diet of tope undergoes ontogenetic shifts, with immature tope consuming more benthic invertebrates than adults, and adults having a higher proportion of cephalopods in their diet (Lucifora et al., 2006). This difference would allow immature tope to maintain smaller home ranges, explaining the shallow depth range of small tope, while mature individuals may have to undertake wider migrations to follow prey such as Atlantic mackerel, Scomber scombrus. The mackerel stock in the northeast Atlantic comprises three spawning units: southern, western and North Sea (Jansen et al., 2013). The western and southern components undertake seasonal north/south movements, with the western component traveling west off Ireland during the spring and summer and the southern spawning component moving up from the Bay of Biscay, along the English Channel and Irish Sea. Both components return to the Bay of Biscay over winter (Lockwood, 1978; Jansen 
et al., 2013). This may at least partly account for the movement observed by tag 153233 , the mature male moving in relation to the western mackerel movements off the shelf edge. The archival depth data from the electronic tags also suggest a seasonal change in diet in three of the four tagged tope. Prey species migrations may also be accountable for the recaptures of mature male tope observed in Iceland and the Azores.

All tope tagged with electronic tags displayed diurnal migrations to some degree while in shallower waters, suggesting exploitation of similar resources. This was mostly in the form of standard or crepuscular vertical migration, consistent with vertical behaviors observed in other areas (West and Stevens, 2001; Cuevas et al., 2014; Rogers et al., 2017). The strength of the cyclic pattern varied temporally between individuals, which may reflect experience of different thermal regimes. In other species of elasmobranch, patterns of diel behavior in coastal areas has been linked to thermal stratification of the water column, with well-mixed waters suppressing regular cyclic movements and stratified waters promoting diurnal movements (Queiroz et al., 2010). The changes in depth behavior observed in the archival and PSAT tags suggest that tope undertake at least three different foraging strategies in deeper waters in the northeast Atlantic determined by the local abundance of prey species. The move to deep water was in winter months, either November (5159) or January (2089 and 153233). Once in the deep-water habitat, tope 5159 remained at depth (below $500 \mathrm{~m}$ ) and diurnal movement broke down, suggesting that 5159 may have been foraging in the deep scattering layer. Tope 2089 and 153233 however, undertook large vertical movements, traveling from bathyal waters as deep as $600 \mathrm{~m}$ to surface waters in just over a 24 -h cycle. This suggests that tracking of vertically migrating prey species, such as squid, similar to behavior observed in tope in the southern hemisphere (West and Stevens, 2001). It appears that male tope, at least, may change their foraging behaviors even in oceanic waters. Tope 153223 only appeared to utilize the deep-water habitat in January, 2 weeks after it crossed the shelf edge to a deeper water environment. This suggests that for the first 2 weeks of occupying oceanic waters, it remained foraging in waters shallower than $300 \mathrm{~m}$ before switching to a different foraging strategy, probably involving a different species in deeper water, which given the geographic variation observed in tope diet compositions is highly probable (Ellis et al., 1996; West and Stevens, 2001; Morato et al., 2003; Lucifora et al., 2006; Torres et al., 2014). This variation in oceanic foraging strategies is similar to that observed in blue sharks in oceanic waters (Queiroz et al., 2010). There was also proof that some mature tope are able to maintain foraging in shallow waters over winter, as tope 2036 remained in waters $<100 \mathrm{~m}$ over winter. Without geolocational estimates, it is not possible to say whether this tope moved over the shelf edge but remained in shallow waters, or whether it remained in shelf waters.

The results presented here provide the most comprehensive overview of tope movements and distributions in the northeast Atlantic, an area from which such data have been lacking. The effectiveness of area-based management strategies such as Marine Protected Areas (MPAs) for mobile species is not always clear (Bonfil, 1999; Hilborn et al., 2004). For elasmobranchs, many of which are strong k-strategists (Stevens et al., 2000; Ellis et al., 2005; Camhi et al., 2009), it has been suggested that MPAs are most effective for younger age classes of mobile species with limited home ranges (Heupel and Simpfendorfer, 2005; Kinney and Simpfendorfer, 2009). However, reliance on management of tope nursery areas in Australia in the 1950s failed; one of the earliest attempts to use spatial management of an elasmobranch (Stevens, 2002). Despite spatial management of nursery areas, tope stocks continued to decline severely as juveniles moving out of the nursery sites, which they are now known to do after 2 years (McAllister et al., 2015), were immediately vulnerable to exploitation before they had a chance to reproduce (Kinney and Simpfendorfer, 2009). This attests that management cannot depend on spatial protection of nursery areas alone. Other areas where spatial management may be considered are those that meet two criteria: (1) The population exhibits site fidelity to the area, ensuring the long-term effectiveness of any protection. (2) There are conflicts that pose a disproportionality high risk to the population in that area. As demonstrated in this study, the coastal environment provides many important habitats for tope which they utilize for critical life history events such as nursery grounds and mating, and tope do display site fidelity to some of these areas. Coastal development projects, such as renewable energy, have the potential to create ongoing impacts at these sites. This potential for conflict and impact should be thoroughly investigated to ascertain the potential effect they could have on northeast Atlantic tope. Spatial management at such sites could be used as part of a wider management strategy for the species to benefit multiple life stages. If spatial management is to be used, it is essential that it is based on good science to prevent the creation of "paper parks" and this approach should be used in conjunction with wider management measures. Due to the limited depth and geographic range of juvenile tope, nursery grounds in UK waters do already, to some extent, naturally benefit from a degree of de facto fisheries protection. However, due to the evidence from Australia (Kinney and Simpfendorfer, 2009), it is apparent that the protection of all age classes is vital to ensure the population's continuity (Kinney and Simpfendorfer, 2009). Mature tope in UK waters are protected by either a prohibition on landing (Scotland) or a low Total Allowable Catch (rest of UK), however, their capacity for wide ranging movements take them beyond these protections into other countries or international jurisdiction, placing them at risk of fisheries interactions. This highlights the need for species management to be conducted via an international unified management plan, using tools such as the Convention for Migratory Species, with pressure on all countries with waters in the populations range to adopt appropriate management strategies. With many migratory species displaying similarly complicated movements, the need for unified management plans at an international level should be a priority. Furthermore, full understanding of the drivers behind a population's movements are essential in order to allow for effective management to be implemented, this should involve simultaneous tracking of both predator and prey species throughout the target species distribution in order to pick up temporal variation and response to prey movements. This should help separate movements based 
on diet, which will affect the entire population, from movements based on reproduction which may only effect mature females. For the northeast Atlantic tope, we recommend further PSAT tagging of mature individuals of both gender, with focus on the latitudinal extremes (both north and south) to help identify migratory strategies. Determining the movements of small juvenile tope would also be advantageous and could be undertaken using data loggers and acoustic telemetry.

\section{DATA AVAILABILITY STATEMENT}

All data from the mark and recapture studies from the UK, Glasgow Museums and Scottish Shark tagging programmes are available upon request from the Scottish Sea Anglers Conservation Network, but applicants should be aware the data may be subject to restrictions due to sensitivities around exact locations of angler marks. Filtered DATRAS data is available from the authors upon request or from https:// datras.ices.dk/. Archival data is available upon request from the authors.

\section{ETHICS STATEMENT}

The animal study was reviewed and approved by Marine Scotland Science.

\section{AUTHOR CONTRIBUTIONS}

JT led on the conception and design of this work, undertook all field work, made a substantial contribution to analysis and created and assembled comments on all drafts of this manuscript. FN provided substantial contributions to the conception or design of the work, subsequent analysis, also advised on tagging methodology, provided training for archival tagging work and provided comment during drafting and revising of the manuscript. IB provided substantial contributions to the

\section{REFERENCES}

Afonso, A. S., and Hazin, F. H. (2015). Vertical movement patterns and ontogenetic niche expansion in the tiger shark, Galeocerdo cuvier. PLoS ONE 10:e0116720. doi: 10.1371/journal.pone.0116720

Andrews, K. S., Williams, G. D., Farrer, D., Tolimieri, N., Harvey, C. J., Bargmann, G., et al. (2009). Diel activity patterns of sixgill sharks, Hexanchus griseus: the ups and downs of an apex predator. Anim. Behav. 78, 525-536. doi: 10.1016/j.anbehav.2009.05.027

Bonfil, R. (1999). "Marine protected areas as a shark fisheries management tool," in Proceedings of the 5th Indo-Pacific Fish Conference Noumea, 1997 (Paris: Societe Francaise d'Ichtyologie, Paris and Istitut de Recherche pour le Developement), 217-230.

Bovcon, N. D., Cochia, P. D., Navoa, X., Ledesma, P., Caille, G. M., and Baigun, C. R. (2018). First report on a pupping area of the tope shark Galeorhinus galeus (Carcharhiniformes, Triakidae) in the south-west Atlantic. J. Fish Biol. 93, 1229-1232. doi: 10.1111/jfb.13781

Bres, M. (1993). The behaviour of sharks. Rev. Fish Biol. Fish. 3, 133-159. doi: 10.1007/BF00045229

Camhi, M., Valenti, S., Fordham, S., Fowler, S., and Gibson, C. (2009). The Conservation Status of Pelagic Sharks and Rays: Report of the IUCN Shark acquisition and interpretation of the Mark and Recapture data, assisted all field work and provided comment on the manuscript. $\mathrm{L}-\mathrm{AH}$ gained funding via SIORC, assisted on field work for the deployment of the archival tags in 2014 and provided comment during drafting and revising of the manuscript. DB provided substantial contributions to the analysis of the data and provided comment during drafting and revising of the manuscript. LN and CJ provided substantial contributions to the conception and design of the work, subsequent analysis, and provided comment during drafting, and revising of the manuscript.

\section{FUNDING}

The Marine Alliance for Science and Technology for Scotland (MASTS) provided funding via a Ph.D. studentship and through the community project SIORC (Sharks, skate, and rays in the offshore and coastal regions of Scotland). MASTS was funded by the Scottish Funding Council (grant reference HR09011) and contributing institutions. This work was supported by the Fisheries Society for the British Isles and Scottish Natural Heritage.

\section{ACKNOWLEDGMENTS}

Thank you to Ken Collins, Richard Sutcliffe, and the Scottish Shark Tagging Programme for the mark and recapture data from the UK, Glasgow Museums and Scottish shark Tagging programmes for the data and all the anglers that have contributed data over the years. Thank you to the members of the public who kindly returned the Lotek tags found washed up on beaches. Thank you Barbara Pereira whose help in retrieving the recaptured Star-Oddi tag from Portugal was invaluable as well as the unnamed fishermen who returned the tag in the first place. Thank you to the funders, MASTS, SNH, and the FSBI and to the Scottish Sea Angling Conservation Network for the purchase of the PSAT tag.
Specialist Group Pelagic Shark Red List Workshop. IUCN Species Survival Commission's Shark Specialist Group.

Capapé, C., Ben Souissi, J., Mejri, H., Guelorget, O., and Hemida, F. (2005). The reproductive biology of the school shark, Galeorhinus galeus Linnaeus 1758 (Chondrichthyes: Triakidae), from the Maghreb shore (southern Mediterranean). Acta Adriatica 46:109.

Carrier, J., Pratt, H., and Castro, J. (2004). "Reproductive Biology of Elasmobranchs," in Biology of Sharks and Their Relatives, eds J. Musick, J. Carrier, and M. Heithaus (Boca Raton, FL: CRC Press), 269-286. doi: 10.1201/9780203491317.ch10

Carrier, J. C., Musick, J. A., and Heithaus, M. R. (2012). Biology of Sharks and Their Relatives, 2nd Edn. Boca Raton, FL: CRC Press. doi: 10.1201/b11867

Colloca, F., Scannella, D., Geraci, M.-L., Falsone, F., Giusto, B., Vitale, S., et al. (2019). British sharks in Sicily: records of long-distance migration of tope shark (Galeorhinus galeus) from the north-eastern Atlantic to the Mediterranean Sea. Mediterr.Mar. Sci. 20, 309-313. doi: 10.12681/mms. 18121

Compagno, L. J. V. (1984). An Annotated and Illustrated Catalogue of Shark Species Known to Date, Part 2: Carcharhiniformes, Vol. 4.

Cuevas, J. M., García, M., and Di Giacomo, E. (2014). Diving behaviour of the critically endangered tope shark Galeorhinus galeus in the natural 
reserve of Bahia San Blas, northern Patagonia. Anim. Biotel. 2:11. doi: 10.1186/2050-3385-2-11

DiBattista, J. D., Feldheim, K. A., Thibert-Plante, X., Gruber, S. H., and Hendry, A. P. (2008). A genetic assessment of polyandry and breeding-site fidelity in lemon sharks. Mol. Ecol. 17, 3337-3351. doi: 10.1111/j.1365-294X.2008.03833.x

Economakis, A., and Lobel, P. (1998). Aggregation behavior of the grey reef shark, Carcharhinus amblyrhynchos, at Johnston Atoll, Central Pacific Ocean. Environ. Biol. Fish. 51, 129-139. doi: 10.1023/A:1007416813214

Ellis, J., Cruz-Martinez, A., Rackham, B., and Rogers, S. (2005). The distribution of chondrichthyan fishes around the British Isles and implications for conservation. J. Northwest Atl. Fish. Sci. 35, 195-213. doi: 10.2960/J.v35.m485

Ellis, J. R., Pawson, M. G., and Shackley, S. E. (1996). The comparative feeding ecology of six species of shark and four species of ray (Elasmobranchii) in the North-East Atlantic. J. Mar. Biol. Assoc. U.K. 76, 89-106. doi: 10.1017/S0025315400029039

Feldheim, K. A., Gruber, S. H., and Ashley, M. V. (2002). The breeding biology of lemon sharks at a tropical nursery lagoon. Proc. R. Soc. Lond. Ser. B 269, 1655-1661. doi: 10.1098/rspb.2002.2051

Fitzmaurice, P., Keirse, G., Green, P., and Clarke, M. (2003). Tope Tagging in Irish Waters (1970-2002). Central Fisheries Board.

Gore, M. A., Rowat, D., Hall, J., Gell, F. R., and Ormond, R. F. (2008). Transatlantic migration and deep mid-ocean diving by basking shark. Biol. Lett. 4, 395-398. doi: $10.1098 / \mathrm{rsbl} .2008 .0147$

Grubbs, R. D. (2010). “Ontogenetic shifts in movements and habitat use," in Sharks and Their Relatives II: Biodiversity, Adaptive Physiology, and Conservation, eds J. Musick, J. Carrier, and M. Heithaus (Boca Raton, FL: CRC Press), 319-350. doi: 10.1201/9781420080483-c7

Gruber, S. H., Nelson, D. R., and Morrissey, J. F. (1988). Patterns of activity and space utilization of lemon sharks, Negaprion brevirostris, in a shallow Bahamian lagoon. Bull. Mar. Sci. 43, 61-76.

Hanchet, S. (1991). Diet of spiny dogfish, Squalus acanthias Linnaeus, on the east coast, South Island, New Zealand. J. Fish Biol. 39, 313-323. doi: 10.1111/j.1095-8649.1991.tb04365.x

Heupel, M. R., and Simpfendorfer, C. A. (2005). Using acoustic monitoring to evaluate MPAs for shark nursery areas: the importance of long-term data. Mar. Technol. Soc. J. 39, 10-18. doi: 10.4031/002533205787521749

Hilborn, R., Stokes, K., Maguire, J.-J., Smith, T., Botsford, L. W., Mangel, M., et al. (2004). When can marine reserves improve fisheries management? Ocean Coast. Manag. 47, 197-205. doi: 10.1016/j.ocecoaman.2004.04.001

Holden, M. J., and Horrod, R. G. (1979). The migrations of tope, Galeorhinus galeus (L), in the eastern North Atlantic as determined by tagging. J. Conseil 38, 314-317. doi: 10.1093/icesjms/38.3.314

Howey-Jordan, L. A., Brooks, E. J., Abercrombie, D. L., Jordan, L. K., Brooks, A., Williams, S., et al. (2013). Complex movements, philopatry and expanded depth range of a severely threatened pelagic shark, the oceanic whitetip (Carcharhinus longimanus) in the western North Atlantic. PLoS ONE 8:e56588. doi: 10.1371/journal.pone.0056588

Hueter, R. E., Heupel, M. R., Heist, E. J., and Keeney, D. B. (2005). Evidence of philopatry in sharks and implications for the management of shark fisheries. J. Northwest Atlantic Fish. Sci. 35, 239-247. doi: 10.2960/J.v35.m493

Hurst, R. J., Bagley, N. W., McGregor, G. A., and Francis, M. P. (1999). Movements of the New Zealand school shark, Galeorhinus galeus, from tag returns. New Zeal. J. Mar. Fresh. Res. 33, 29-48. doi: 10.1080/00288330.1999. 9516854

Hussey, N. E., McCarthy, I. D., Dudley, S. F., and Mann, B. Q. (2009). Nursery grounds, movement patterns and growth rates of dusky sharks, Carcharhinus obscurus: a long-term tag and release study in South African waters. Mar. Fresh. Res. 60, 571-583. doi: 10.1071/MF08280

Jansen, T., Campbell, A., Brunel, T., and Clausen, L. W. (2013). Spatial segregation within the spawning migration of North Eastern Atlantic Mackerel (Scomber scombrus) as indicated by juvenile growth patterns. PLOS ONE 8:e58114. doi: 10.1371/journal.pone.0058114

Jorgensen, S. J., Reeb, C. A., Chapple, T. K., Anderson, S., Perle, C., Van Sommeran, S. R., et al. (2010). Philopatry and migration of pacific white sharks. Proc. R. Soc. B 277, 679-688. doi: 10.1098/rspb.2009.1155

Kinney, M. J., and Simpfendorfer, C. A. (2009). Reassessing the value of nursery areas to shark conservation and management. Conserv. Lett. 2, 53-60. doi: 10.1111/j.1755-263X.2008.00046.x
Klimley, A. P. (1987). The determinants of sexual segregation in the scalloped hammerhead shark, Sphyrna lewini. Environ. Biol. Fish. 18, 27-40. doi: 10.1007/BF00002325

Little, W. (1995). Common skate and tope: first results of Glasgow Museum's tagging study. Glasgow Nat. 22, 455-466.

Little, W. (1998). Tope and skate tagging off west Scotland. Glaucus 9, 36-38.

Lockwood, S. J. (1978). Mackerel: A Problem in Fish Stock Assessment. Laboratory Leaflet, Maff Fisheries Laboraory, Lowestoft, 44.

Lucifora, L., Menni, R., and Escalante, A. (2004). Reproductive biology of the school shark, Galeorhinus galeus, off Argentina: support for a single south western Atlantic population with synchronized migratory movements. Environ. Biol. Fish. 71, 199-209. doi: 10.1007/s10641-004-0305-6

Lucifora, L. O., García, V. B., Menni, R. C., and Escalante, A. H. (2006). Food habits, selectivity, and foraging modes of the school shark Galeorhinus galeus. Mar. Ecol. Prog. Ser. 315, 259-270. doi: 10.3354/meps315259

McAllister, J. D., Barnett, A., Lyle, J. M., and Semmens, J. M. (2015). Examining the functional role of current area closures used for the conservation of an overexploited and highly mobile fishery species. ICES J. Mar. Sci. 72, 2234-2244. doi: 10.1093/icesjms/fsv079

McMillan, M. N., Huveneers, C., Semmens, J. M., and Gillanders, B. M. (2018a). Natural tags reveal populations of Conservation Dependent school shark use different pupping areas. Mar. Ecol. Prog. Ser. 599, 147-156. doi: $10.3354 /$ meps 12626

McMillan, M. N., Huveneers, C., Semmens, J. M., and Gillanders, B. M. (2018b). Partial female migration and cool-water migration pathways in an overfished shark. ICES J. Mar. Sci. 76, 1083-1093. doi: 10.1093/icesjms/fsy181

Morato, T., Solà, E., Grós, M. P., and Menezes, G. (2003). Diets of thornback ray (Raja clavata) and tope shark (Galeorhinus galeus) in the bottom longline fishery of the Azores, northeastern Atlantic. Fish. Bull. 101, 590-602.

Mourier, J., and Planes, S. (2013). Direct genetic evidence for reproductive philopatry and associated fine-scale migrations in female blacktip reef sharks (Carcharhinus melanopterus) in French Polynesia. Mol. Ecol. 22, 201-214. doi: $10.1111 / \mathrm{mec} .12103$

Mucientes, G. R., Queiroz, N., Sousa, L. L., Tarroso, P., and Sims, D. W. (2009). Sexual segregation of pelagic sharks and the potential threat from fisheries. Biol. Lett. 5, 156-159. doi: 10.1098/rsbl.2008.0761

Munoz-Chapuli, R. (1984). Ethologie de la reproduction chez quelques requins de l'Antlantique Nord-East. Cybium 8, 1-14.

Neat, F., Pinto, C., Burrett, I., Cowie, L., Travis, J., Thorburn, J., et al. (2014). Site fidelity, survival and conservation options for the threatened flapper skate (Dipturus cf. intermedia). Aquat. Conserv. Mar. Freshw. Ecosyst. 25, 6-20. doi: $10.1002 /$ aqc. 2472

Olsen, A. (1954). The biology, migration, and growth rate of the school shark, Galeorhinus australis (Macleay)(Carcharhanidae) in the South-eastern Australian waters. Mar. Fresh. Res. 5, 353-410. doi: 10.1071/MF9540353

Papastamatiou, Y. P., Meyer, C. G., Carvalho, F., Dale, J. J., Hutchinson, M. R., and Holland, K. N. (2013). Telemetry and random-walk models reveal complex patterns of partial migration in a large marine predator. Ecology 94, 2595-2606. doi: 10.1890/12-2014.1

Pratt, H. L., and Carrier, J. C. (2001). A review of elasmobranch reproductive behavior with a case study on the nurse shark, Ginglymostoma cirratum. Environ. Biol. Fish. 60, 157-188. doi: 10.1023/A:1007656126281

Priede, I. G., Rainer, F., Bailey, D. M., Bergstad, O. A., Collins, M. A., Dyb, J. E., et al. (2006). The absence of sharks from Abyssal regions of the world's oceans. Proc. R. Soc. B Biol. Sci. 273, 1435-1441 doi: 10.1098/rspb.2005.3461

Queiroz, N., Humphries, N. E., Noble, L. R., Santos, A. M., and Sims, D. W. (2010). Short-term movements and diving behaviour of satellite-tracked blue sharks Prionace glauca in the northeastern Atlantic Ocean. Mar. Ecol. Prog. Ser. 406, 265-279. doi: 10.3354/meps,.08500

R Core Team (2013). R: A Language and Environment for Statistical Computing. R Foundation for Statistical Computing, Vienna, Austria. Available online at: http://www.R-project.org/

Ripley, W. (1946). "The soup fin sharks and the fishery," in Fish Bulletin No. 64. The Biology of the Soupfin Galeorhinus zyopterus and Biochemical Studies of the Liver (California Division of Fish and Game), 184.

Robbins, R. L. (2007). Environmental variables affecting the sexual segregation of great white sharks Carcharodon carcharias at the Neptune Islands South Australia. J. Fish Biol. 70, 1350-1364. doi: 10.1111/j.1095-8649.2007.01414.x 
Rogers, P. J., Knuckey, I., Hudson, R. J., Lowther, A. D., and Guida, L. (2017). Post-release survival, movement, and habitat use of school shark Galeorhinus galeus in the Great Australian Bight, southern Australia. Fish. Res. 187, 188-198. doi: 10.1016/j.fishres.2016.11.011

Rösch, A., and Schmidbauer, H. (2014). WaveletComp: Computational Wavelet Analysis. R package version 1.0. Available online at: https://CRAN.R-project. org/package $=$ WaveletComp

Sims, D. W., Southall, E. J., Richardson, A. J., Reid, P. C., and Metcalfe, J. D. (2003). Seasonal movements and behaviour of basking sharks from archival tagging: no evidence of winter hibernation. Mar. Ecol. Prog. Ser. 248, 187-196. doi: $10.3354 / \operatorname{meps} 248187$

Speed, C. W., Field, I. C., Meekan, M. G., Bradshaw, C. J., and others (2010). Complexities of coastal shark movements and their implications for management. Mar. Ecol. Prog. Ser. 408, 275-293. doi: 10.3354/meps08581

Stevens, J. (2002). “The role of protected areas' in elasmobranch fisheries management and conservation," in Elasmobranch Biodiversity, Conservation and Management: Proceedings of the International Seminar and Workshop, eds S. L. Fowler, T. M. Reed, and F. A. Dipper (Gland; Cambridge: IUCN SSC Shark Specialist Group; IUCN), 241-242.

Stevens, J. D. (1990). Further results from a tagging study of pelagic sharks in the north-east Atlantic. J. Mar. Biol. Assoc. U.K. 70, 707-720. doi: $10.1017 /$ S0025315400058999

Stevens, J. D., Bonfil, R., Dulvy, N. K., and Walker, P. A. (2000). The effects of fishing on sharks, rays, and chimaeras (chondrichthyans), and the implications for marine ecosystems. ICES J. Mar. Sci. 57, 476-494. doi: $10.1006 /$ jmsc. 2000.0724

Sutcliffe, R. (1994). Twenty Years of Tagging Common Skate and Tope Off the West Coast of Scotland. Shark, Skate and Ray Workshop, London.

Templeman, W. (1976). Transatlantic migrations of spiny dogfish (Squalus acanthias). J. Fish. Res. Board Canada 33, 2605-2609. doi: 10.1139/ f76-308

Thorburn, J., Jones, R., Neat, F., Pinto, C., Bendall, V., Hetherington, S., et al. (2018). Spatial versus temporal structure: implications of inter-haul variation and relatedness in the North-east Atlantic spurdog Squalus acanthias. Aquat. Conserv. Mar. Fresh. Ecosyst. 28, 1167-1180. doi: 10.1002/aqc.2922
Thorburn, J., Neat, F., Bailey, D. M., Noble, L. R., and Jones, C. S. (2015) Winter residency and site association in the Critically Endangered North East Atlantic spurdog Squalus acanthias. Mar. Ecol. Prog. Ser. 526, 113-124. doi: 10.3354/meps11210

Torres, P., da Cunha, R. T., Maia, R., and dos Santos Rodrigues, A. (2014). Trophic ecology and bioindicator potential of the North Atlantic tope shark. Sci. Total Environ. 481, 574-581. doi: 10.1016/j.scitotenv.2014.02.091

Walker, T. (1999). "Galeorhinus galeus fisheries of the world," in Case Studies of the Management of Elasmobranch Fisheries, FAO Fisheries Technical Paper 378/2, ed R. Shotton (Rome: FAO), 728-773.

Wearmouth, V. J., and Sims, D. W. (2008). Sexual segregation in marine fish, reptiles, birds and mammals: behaviour patterns, mechanisms and conservation implications. Adv. Mar. Biol. 54, 107-170. doi: 10.1016/S0065-2881(08)00002-3

Wearmouth, V. J., and Sims, D. W. (2010). Sexual segregation in elasmobranchs. Biol. Mar. Mediterr. 17, 236-239.

West, G. J., and Stevens, J. D. (2001). Archival tagging of school shark, Galeorhinus galeus, in Australia: initial results. Environ. Biol. Fish. 60, 283-298. doi: 10.1023/A:1007697816642

Wheeler, A. (1969). The Fishes of the British Isles and North-West Europe. London: Macmillan.

Wood, S. N. (2001). mgcv: GAMs and generalized ridge regression for R. $R$ News $1,20-25$

Conflict of Interest: The authors declare that the research was conducted in the absence of any commercial or financial relationships that could be construed as a potential conflict of interest.

Copyright (c) 2019 Thorburn, Neat, Burrett, Henry, Bailey, Jones and Noble. This is an open-access article distributed under the terms of the Creative Commons Attribution License (CC BY). The use, distribution or reproduction in other forums is permitted, provided the original author(s) and the copyright owner(s) are credited and that the original publication in this journal is cited, in accordance with accepted academic practice. No use, distribution or reproduction is permitted which does not comply with these terms. 